\title{
Balada da discórdia: o relacionamento entre brancos e índios na poesia de Manuel González Prada - Peru (Séc. XIX)
}

Ruth Cavalcante Neiva ${ }^{1}$

Resumo: No cenário da segunda metade do século XIX, o intelectual Manuel González Prada pensou a respeito do lugar do indígena e a conduta moral do "homem branco" na sociedade peruana. Para examinar essa questão, elegemos a reflexão de quatro baladas que fizeram um reconhecimento da "humanidade do índio" e representaram o modelo de relação entre indígenas e brancos na perspectiva do imaginário do autor. São elas: $L a$ hija del curaca; El chasqui; El mitayo; e Los tres. Esses poemas foram marcados pela confrontação de brancos versus índios. A partir da análise da obra Baladas, acreditamos que González Prada concebeu o Peru como um Estado que ainda não poderia ser interpretado como sendo uma nação. Pensar sobre tal problemática é o propósito deste artigo.

Palavras-chave: Índios; Peru; González Prada.

\section{Ballad of discord: The relationship between whites and indians in the poetry of Manuel González Prada}

\begin{abstract}
In the scenario of the second half of the nineteenth century, the intellectual Manuel González Prada thought about the place of the indians and about the moral conduct of the "white man" in peruvian society. To examine this question, we elected the reflection of four ballads that aimed to recognize the "humanity of the indian" and represented the model of relationship between indians and whites in the author's perspective. They are: La hija del curaca; El chasqui; El mitayo and Los tres. These poems were marked by confrontation of whites versus indians. From the analysis of Baladas, we believe that González Prada conceived Peru as a State that could not yet be interpreted as a nation. To think about this matter is the purpose of this article.
\end{abstract}

\footnotetext{
${ }^{1}$ Doutoranda em História pela Universidade Federal do Espírito Santo (UFES), Brasil. Pesquisa em andamento: "O problema indígena" na sociedade peruana do fim do século XIX e o princípio do século $X X ”$ ”. Bolsista CAPES. E-mail: donaruth26@hotmail.com
}

\section{GANPHLAC}

Revista Eletrônica da ANPHLAC, ISSN 1679-1061, №. 25, p. 161-182, Jul./Dez., 2018.

http://revista.anphlac.org.br 
Keywords: Indians; Peru; González Prada.

Artigo recebido em: 31/12/2017

Artigo aprovado em: 07/08/2018

A ruptura política do Vice-reinado do Peru com a metrópole espanhola foi traumática e se deu, sobretudo, graças à intervenção armada dos "Libertadores da América": José de San Martín e Simon Bolívar. ${ }^{2}$ Em 1821, os exércitos de San Martín natural de Yapeyú, Vice-reinado do Rio da Prata - venceram no campo de batalha as forças que defendiam o poderio da Coroa, sendo que naquele mesmo ano declarou a independência do país. Contudo, o novo Estado nasceu em meio a uma guerra civil, pois houve resistência da antiga Metrópole e de parte dos criollos de Lima contra as forças que advogavam em prol da autonomia peruana, fazendo com que o confronto para assegurar a soberania do novo país fosse violento e permanecesse durante anos. A oposição dos segmentos então ligados aos interesses de Madri só fora sufocada entre 1823 e 1824, após sangrentas batalhas, quando os independentistas contaram com o apoio decisivo dos exércitos liderados por Simon Bolívar - proveniente de Caracas, Capitania Geral da Venezuela. As forças de Bolívar sitiaram e ocuparam Lima e, com isso, conseguiram firmar a "libertação" peruana (BONILLA; SPALDING, 1972, p. 1520).

A independência do Peru se consolidou porque contou com o apoio de "exércitos invasores". Os principais líderes independentistas, San Martín e Simon Bolívar, eram homens provenientes de "outras terras", que receberam o apoio de uma parcela da elite criolla provinciana e limenha e um tímido auxílio da população local de

\footnotetext{
${ }^{2}$ É importante salientar que o Vice-reinado do Peru era a possessão mais importante e rica da monarquia espanhola na América do Sul. Sua elite dirigente, por ser mais intensivamente controlada pela Coroa, estava mais intimamente ligada aos interesses de Madri. "Si en Buenos Aires y en Caracas la aspiración a la independencia de la burguesía criolla nació del deseo de superar su inferioridad política y alcanzar en este campo la hegemonía plena para hacerla conciliable con su poderío económico, ello no ocurrió ni podía ocurrir en el Perú. Toda la fuerza anterior de la clase hegemónica peruana, por el contrario, se nutrió de su vinculación con la metrópoli. Internamente no existieron ni las bases materiales ni los fundamentos ideológicos que impulsaran a la liberación. Tal vez más bien, la esperanza de un reforzamiento de la situación colonial y lamentos por el esplendor perdido". (BONILLA; SPALDING, 1972. p. 24).
}

\section{CANPHLAC}

Revista Eletrônica da ANPHLAC, ISSN 1679-1061, №. 25, p. 161-182, Jul./Dez., 2018.

http://revista.anphlac.org.br 
modo geral. Isso significa que a emancipação peruana foi orquestrada de "fora para dentro". Porém, para os "Libertadores da América", era estratégico e crucial aniquilar e expulsar as forças espanholas do Vice-reinado do Peru, o maior bastião da lealdade à Espanha na América do Sul.

Heraclio Bonilla e Karen Spalding, no artigo La Independencia en el Perú: las palabras y los hechos, defenderam que a emancipação peruana "conquistada" em 1821 significou tão somente uma mudança do regime político, em que o Peru deixou de fazer parte do Império Espanhol para se converter em um novo Estado-nação. ${ }^{3}$ Todavia, esses intérpretes afirmaram que no pós-independência não houve uma mudança significativa nas bases sociais e econômicas da jovem república. O Peru permaneceu em uma posição de dependência e de subordinação em face à Europa, destacando-se a sujeição comercial e financeira em relação ao capital inglês. Além disso, em termos sociais, praticamente não houve mudanças substanciais, uma vez que o corpo social peruano continuou estratificado (BONILLA; SPALDING, 1972, p. 15-64).

Mesmo com a inauguração da República, os conflitos herdados do período colonial permaneceram e a "nova comunidade nacional" durante o período republicano, no século XIX e em parte do século XX, permaneceu segregada em grupos sociais distintos, hierarquizados e bem definidos de acordo com um critério racial/cultural.

Como es sabido, el régimen colonial no favoreció un sistema integrador, españoles y indios constituyeron no solo republicas distintas sino inconexas, mundos paralelos a los que incluso se les prohibió mantener contacto. La separación, producto no solo de la ley sino, aún más, de la geografía y del sistema socioeconómico, continuó en la República dado que la independencia no alteró mayoritariamente la estructura social (HOLGUÍN, 2006, p. 69).

A sociedade peruana do pós-independência estava dividida em uma estrutura social na qual os criollos, grupo dominante, exerciam controle sobre os demais

\footnotetext{
${ }^{3}$ No curso do século XIX e princípio do século XX, o Estado-nação foi pensado como uma forma legitimadora da nação. Nessa perspectiva, a nação se encarnava em um Estado transcendente que, a partir das suas instituições, dava forma e legitimidade à identidade nacional e congregava os cidadãos em uma comunidade, encarregando-se também de criar uma cultura passada e de formar o caráter nacional (GIL, 2002, p. 9-20).
}

\section{CANPHLAC}

Revista Eletrônica da ANPHLAC, ISSN 1679-1061, №. 25, p. 161-182, Jul./Dez., 2018.

http://revista.anphlac.org.br 
segmentos do Estado: os índios, os negros, os imigrantes asiáticos ${ }^{4}$ e os mestiços. Porém, apesar dessa segregação, devemos levar em consideração a secular infração das normas sociais pré-estabelecidas. Ou seja, não obstante as tradicionais proibições de aproximação entre os grupos sociais, houve sim convivência, inter-relação, relacionamentos amorosos e de amizade entre os indivíduos destes "povos distintos" (HOLGUÍN, 2006, p. 69).

Inspirando-nos na obra Comunidades imaginadas, de Benedict Anderson, acreditamos que a nação peruana foi imaginada e construída a partir da perspectiva das elites criollas. Anderson mostra que a nação foi pensada como uma entidade limitada, soberana e imaginada. Ela é limitada porque possui fronteiras finitas e não se imagina coextensiva com a humanidade, ou seja, não sonha que todos os membros da raça humana se juntem à sua nação. Também é soberana porque sonha em ser livre e, o símbolo dessa liberdade é o Estado soberano. Por fim, a nação é uma comunidade imaginada porque seus membros imaginam uma comunhão entre os seus compatriotas.

A nação é uma entidade "inventada" porque não existe nenhuma "comunidade natural em torno da qual se possa reunir as pessoas que constituem um determinado agrupamento nacional, ela precisa ser inventada, imaginada" (SILVA, 2012, p. 85). Isso significa que no processo da construção de uma identidade nacional, é necessário criar e fabricar "laços imaginários" que permitam ligar as pessoas que sem eles seriam tão somente indivíduos isolados sem nenhum sentimento de terem qualquer coisa em comum.

Schwarcz nos esclarece que as "nações imaginadas" possuem uma autenticidade emocional profunda e devem fazer sentido para a "alma" dos indivíduos, sendo idealizadas como comunidades que, independentemente das hierarquias e desigualdades efetivamente existentes, sempre serão concebidas como estruturas de camaradagem

\footnotetext{
${ }^{4}$ A partir de 1849, um enorme contingente de coolíes - asiáticos provenientes principalmente da China chegaram em massa ao Peru com a finalidade de substituir a antiga mão de obra escrava na agricultura da costa e nas ilhas guaneras. Esses trabalhadores tinham uma condição laboral semelhante à dos africanos e afrodescendentes escravizados nas Américas, pois para pagarem suas passagens ao Peru, suas vestimentas e alimentação, assumiam uma dívida exorbitante com os patrões que os obrigava a trabalhar por um período de sete a oito anos para pagar os seus débitos. Isso significa que os coolíes foram submetidos a um brutal regime de exploração do trabalho (CONTRERAS; CUETO, 2007. p. 136-142).
}

\section{GANPHLAC}

Revista Eletrônica da ANPHLAC, ISSN 1679-1061, №. 25, p. 161-182, Jul./Dez., 2018.

http://revista.anphlac.org.br 
horizontal, consequentemente estabelecendo-se a noção de um "nós coletivo", capaz de irmanar relações em tudo distintas (SCHWARCZ, 2008, p. 10-16).

"Imaginar" a nação peruana no cenário do pós-independência não foi uma tarefa fácil. Diversos fatores dificultaram a construção de uma nação coesa entre o século XIX e a primeira metade do XX. Elementos como a herança da estrutura social estratificada do período colonial, o racismo, o problema da incomunicação linguística, a diversidade de tradições e culturas, o isolamento favorecido pela extensão territorial e a geografia acidentada, entre outros elementos, fizeram com que houvesse uma dificuldade na elaboração da construção de uma identidade nacional para o país (HOLGUíN, 2006, p. $66)$.

Nesse cenário, os criollos negaram como traço da identidade ${ }^{5}$ nacional os costumes e os hábitos dos negros africanos, dos aimarás, quéchuas e outras etnias, transformando a República peruana em uma Nación criolla. Nesse sentido, quem arquitetava e comandava o destino político do novo Estado-nação eram quase que exclusivamente os criollos, portadores de privilégios e direitos especiais dos quais os índios e os demais grupos étnicos do país eram privados (JESUS, 2015, p. 44-47).

No processo da construção do Estado-nação, os setores dirigentes do Peru do século XIX adotaram tão somente a sua herança cultural espanhola em detrimento do legado indígena, mantendo-se ligados de forma estreita à mentalidade e aos valores ocidentais. Assim, eles conservaram o castelhano como o único idioma oficial da República, mantiveram o catolicismo como a única prática religiosa legítima, além de terem inspirarado as suas novas instituições cívico-políticas e o sistema judiciário em uma matriz exclusivamente europeia (HOLGUÍN, 2006, p. 66-69). Isso significa que os criollos invisibilizaram a variedade de culturas existentes no território nacional, não levando em consideração os costumes dos aimarás, quéchuas e outras etnias que

\footnotetext{
${ }^{5}$ Tomás Tadeu Silva nos esclarece que a identidade nunca é uma "essência" dada pela natureza ou pela cultura. Ela não é fixa, nem coerente e tampouco homogênea, unificada e acabada. Pelo contrário, a identidade é sempre uma construção, um processo de produção que está ligado a estruturas discursivas e narrativas, estando sempre em conexão com as relações de poder e aos sistemas de representação. Representar significa dizer "a identidade é essa"; "isto é a identidade", logo, quem tem o poder de representar, tem o poder de definir e determinar a identidade (SILVA, 2012, p. 89-97).
}

\section{CANPHLAC}

Revista Eletrônica da ANPHLAC, ISSN 1679-1061, №. 25, p. 161-182, Jul./Dez., 2018.

http://revista.anphlac.org.br 
secularmente viviam na região. Ou seja, nesse contexto não houve um reconhecimento de que a cultura peruana era um caudal heterogêneo.

No pós-independência, as tentativas de transformação do status quo da sociedade encontraram muitas barreiras. Por exemplo, tanto San Martín quanto Simon Bolívar decretaram a abolição do tributo indígena. Em 1821, San Martín ordenou que fossem extintos "los servicios, mitas, pongos, encomiendas y yanaconaje, así como todo servicio personal bajo pena de expatriación para los infractores [...] pues ellos son hijos y ciudadanos del Perú y con el nombre de peruanos deben ser conocidos" (TORD, 1978, p. 28). Por sua vez, Bolívar, em 1824, proibiu qualquer tipo de servidão pessoal dos indígenas e estipulou que eles fossem declarados proprietários legais das suas terras. Todavia, em 1826, os legisladores peruanos restabeleceram o tributo indígena trocando o seu nome para uma nova denominação que ficou conhecida comumente como “contribuição dos índios" (CONTRERAS, 2013, s/p). Isso significa que a jovem República manteve alguns costumes herdados do período colonial, pois se outrora a população nativa era obrigada a pagar tributos aos "conquistadores", agora os índios tinham que contribuir economicamente e, de forma igualmente compulsória, para com o Estado republicano. Essas taxas que os indígenas se viam obrigados a pagar eram asseguradas pela ordem legal e jurídica daquele momento e consistiam basicamente na entrega de uma parte da produção comunitária e pessoal ao governo local ou prestação de serviços.

Durante praticamente todo o século XIX, e boa parte do século XX, os membros das comunidades indígenas, maioria da população do Peru, também foram excluídos da participação da vida política do Estado-nação. Quando pensamos na atuação e na presença desses elementos nas eleições parlamentares ou presidenciais na era republicana, observamos que eles foram praticamente suprimidos do processo eleitoral. Entre 1821 e 1896, a legislação eleitoral peruana permitia que uma fração dos índios tivesse o direito ao voto, ${ }^{6}$ mas tal privilégio se baseava em um critério censitário (apenas para os que pagavam a "contribuição dos índios") e patrimonial (deveriam ter rendas comprovadas). Na prática, era uma quantidade mínima de indígenas que

\footnotetext{
${ }^{6}$ Já entre 1896 e 1979, eliminou-se e restringiu-se ainda mais o acesso à participação nas eleições, uma vez que a legislação eleitoral peruana não permitia que os analfabetos, isto é, pessoas sem a habilidade de saber ler e escrever em espanhol, tivessem direito ao voto (BALDÍN, 2009, p. 62-67).
}

\section{GANPHLAC}

Revista Eletrônica da ANPHLAC, ISSN 1679-1061, №. 25, p. 161-182, Jul./Dez., 2018.

http://revista.anphlac.org.br 
conseguia preencher os requisitos exigidos para participar como votantes nas eleições (BALDÍN, 2009, p. 62-67).

Baldín, ao analisar as constituições latino-americanas e o tratamento dado aos povos indígenas ao longo do século XIX, alega que existiu uma série de normas legais que garantiram um lugar de subalternidade jurídica aos índios, que não eram reconhecidos como sujeitos com direito a eleger e serem eleitos. A Constituição peruana de 1828 considerava os povos indígenas como incivilizados e como crianças que não sabiam distinguir entre o bem e o mal. Assim, a República do Peru negou ao índio o direito pleno de exercer a sua cidadania (BALDÍN, 2009, p. 70-71).

Foi em meio a tal cenário que o intelectual Manuel González Prada (1844-1918) começou a escrever várias obras criticando o lugar de subalternidade social que o índio ocupava na sociedade do Peru do século XIX e princípio do século XX.

Sobre o autor, podemos destacar que residiu entre 1871 e 1879 em uma fazenda familiar próxima à Lima, localizada no Vale de Mala, onde realizou estudos sobre química e dedicou-se ao cultivo da mandioca. Além disso, devotou-se à leitura de uma gama de autores europeus, com destaque para as obras dos escritores franceses Victor Hugo e Émile Zola. Nesse cenário, aprofundou a sua aprendizagem no alemão e entrou em contato com o pensamento de Nietzsche, Schopenhauer, Spencer e Hegel (BECHELLI, 2005, p. 362).

O cotidiano da vida de González Prada se modificou com o início da Guerra do Pacífico, em 1879, quando foi por livre iniciativa à Lima se alistar no exército. Tornouse Oficial de Reserva e participou diretamente das lutas contra a invasão do Peru por parte dos exércitos chilenos. Durante o período da ocupação chilena no território peruano, nosso autor teve uma intensa atividade intelectual, redigindo diversas poesias e peças teatrais (CANTANELLI, 2009, p. 41).

Desde a sua juventude, González Prada esteve ligado à atmosfera artística e intelectual de Lima. Foi membro do Clube Literário, centrado na figura de Ricardo Palma, um agrupamento que reunia os principais escritores do país e defendia uma literatura socialmente desinteressada e preocupada com questões puramente estéticas. Contudo, devido a divergências internas, juntamente com um grupo heterogêneo de

\section{GANPHLAC}

Revista Eletrônica da ANPHLAC, ISSN 1679-1061, №. 25, p. 161-182, Jul./Dez., 2018.

http://revista.anphlac.org.br 
intelectuais que defendiam que a literatura deveria ter um papel social e político, retirou-se do Clube e fundou o Círculo Literário (SOUZA, 2015, p. 128-132).

Desejoso de promover uma revolução nas "Letras" do país, ao fundar o Círculo, González Prada advogou em prol da "independência literária” dos escritores peruanos em relação à Literatura da Espanha. Acusou os literatos do Peru como José de Espronceda, Ramón de Campoamor e Gustavo Bécquer, de meramente imitar os ícones de literatura da antiga metrópole em pleno século XIX. Por essa razão, exaltou a necessidade de se criar no país uma literatura original que expressasse a autenticidade peruana. Ao primar pela busca da originalidade, inspirou-se no discurso The American scholar (1837), de Ralph Waldo Emerson, que também havia se queixado de que os norte-americanos imitavam à Shakespeare (CHANG-RODRIGUES, 2010, p. 68).

Sobretudo inspirado no escritor Victor Hugo, González Prada incitou os membros do Círculo a utilizarem a literatura como um instrumento capaz de promover uma transformação das mentalidades e dos corações, consequentemente modificando a política e o status quo da sociedade. O grupo teve um papel radical em Lima e, posteriormente, em 1891, acabou dando origem a um partido político, denominado de União Nacional, do qual González Prada foi o primeiro presidente (SOUZA, 2015, p. 129-130).

Segundo José Carlos Mariátegui, os membros do Círculo Literário se intitulavam como o "partido radical da literatura", buscando "civilizar" a sociedade com o poder da pluma. $\mathrm{O}$ intérprete chamou a atenção para o fato de que o pensamento contestador e radical no Peru se originou em meio aos seus literatos. Esse foi um contexto em que a crítica dos escritores extravasou a atmosfera da ficção e adentrou no campo da política, sacudindo uma sociedade que, segundo Mariátegui, se encontrava “adormecida" (MARIÁTEGUI, 2005, p. 228).

Os versos da obra Baladas, de Manuel González Prada, estão inseridos nesse cenário de contestação ao status quo da sociedade. O principal ponto da crítica dos poemas analisados por este trabalho, girou em torno da denúncia sobre o lugar de sujeição, de miséria e de subalternidade que o indígena ocupava na sociedade peruana.

\section{GANPHLAC}


Baladas é uma obra composta por uma série de poemas cuja data de elaboração é indeterminada, mas a principal hipótese é a de que foram escritos a partir de 1870 (CASTELLANOS, 2004, p. 10-12). Gonzalo Portocarrero acredita que essas baladas foram redigidas entre 1871 e 1879 , quando o intelectual peruano residia na fazenda familiar em Tutumo, no Vale de Mala (PORTOCARRERO, 2010, p. 217). Contudo, tal trabalho foi publicado apenas postumamente, em 1939.

Essa obra foi dividida em três partes. O primeiro livro de Baladas retratou os temas que interessam aos propósitos da nossa investigação, uma vez que abordou assuntos que envolviam as lendas, as tradições folclóricas e os problemas da sociedade peruana. A primeira sessão desse trabalho foi publicada separadamente em Santiago, no Chile, em 1935, tendo recebido o título de Baladas Peruanas. O segundo livro de Baladas tratou de assuntos gerais nos quais o leitor foi "transportado" para um mundo medievo e cheio de fantasias. Esses versos foram marcados por ironia e humor, sendo que os cenários geográficos das histórias eram a França, a Rússia, a Espanha, a Grécia e o Japão. A terceira parte da obra em questão foi ainda mais heterogênea, contando com traduções feitas por González Prada de autores alemães, como Goethe, Uhland e Heine. Gostaríamos de frisar que a nossa análise se concentrará no primeiro livro de Baladas, que corresponde à obra Baladas Peruanas.

Ao escrever as suas baladas, González Prada recorreu a um gênero que era muito distante da tradição literária peruana, uma vez que a balada é um poema de origem folclórica e de aparência popular surgida na Alemanha, no contexto da Idade Média. A balada é marcada por um ritmo de musicalidade e se dedica a um tema lendário ou histórico; ela é uma breve "canção-história" que emprega escassos detalhes em sua construção narrativa e é caracterizada pelo objetivismo. A balada é também um poema muito curto feito para ser cantado de forma lenta e melodiosa que se utiliza de uma linguagem simples e narra, comumente uma história que se desenvolve a partir de uma conversa entre dois protagonistas. Além disso, é comum que os versos desse tipo de poesia recorram à criação de um diálogo carregado de dramaticidade, em um jogo de perguntas diretas e respostas curtas e objetivas (MASSAUD, 2004, p. 50).

Por meio da ficção, González Prada criou um relato da história peruana, ou seja, sem se basear em uma documentação historiográfica oficial, construiu uma épica

\section{GANPHLAC}

Revista Eletrônica da ANPHLAC, ISSN 1679-1061, №. 25, p. 161-182, Jul./Dez., 2018.

http://revista.anphlac.org.br 
nacional, uma vez que as suas baladas foram desde a apresentação dos mitos incaicos da criação da terra e a dos homens até ingressarem no período republicano.

O primeiro poema da obra, intitulado Kon, conta como o Deus da tradição andina criou as montanhas, as planícies, os rios e os homens. Baseando-se na mitologia incaica, escreveu baladas como Origen de los incas ${ }^{7}$ e Fundación del Cuzco em que Manco Cápac, fundador do Império Inca e o primeiro governante de Cusco, foi apresentado como um ser divino, sendo o filho do Sol e da Lua e, destinado pelos Deuses, a erguer a metrópole imperial que veio a se chamar $C u z c o$.

Nos versos de La llegada de Pizarro, La cena de Atahualpa e La sombra de Huáscar fantasiou como se deu o processo de invasão e de "conquista" da Espanha sobre o Império Inca, ressaltando em suas baladas a enganação e a violência dos espanhóis para com o imperador Atahualpa. Ao imaginar como era o "mundo peruano" dos tempos coloniais, expressou todo o sofrimento dos indígenas em relação ao regime de servidão ao qual foram submetidos, destacando-se o poema El cacique filicida, ${ }^{8}$ que preferiu assassinar ao seu próprio filho a vê-lo crescer sob uma condição de servo e subjugado aos espanhóis.

Para os propósitos da nossa pesquisa, elegemos a reflexão de quatro baladas que fizeram um reconhecimento da "humanidade do índio" e representaram o modelo de relação entre os índios e os brancos presente no imaginário de González Prada. São elas: La hija del curaca; El chasqui; El mitayo; e Los tres, poemas marcados pela confrontação maniqueísta entre brancos versus índios.

\footnotetext{
${ }^{7}$ Lejos de montes y ríos, // sobre tapices de brumas, // con las alas del deseo, // vuela el Sol tras de la Luna. // La coge, al seno la estrecha, // y en luminosas alturas, // a la faz de Pachakámak, // el divino amor consuma. // Los suspiros y los besos // de polo a polo retumban, // a Cielo y Tierra estremecen // los espasmos de ternura; // y el atónito Universo // en voz de triunfo saluda // al virgen seno rasgado // por la simiente fecunda. // Abre el misterioso nido // de sus entrañas la Luna // y en una isla del gran lago // la celeste prole oculta. // Prole feliz, no sujeta // al oprobio de la cuna // Que en vez de niño inconsciente // es gentil pareja adulta, // en la rica florescencia // del amor y la hermosura: // es Manco Cápac el héroe // de alma benéfica y justa; // es Mama Ocllo la virgen // toda pureza y dulzura (GONZÁLEZ PRADA, 2004, p. 29-30).

${ }^{8}$ Brilla sin nubes la luna, // soplan húmidas las auras, // y las olas, mansamente, // van a morir en la playa. // Con un niño entre los brazos, // el cacique se adelanta // por las juncosas orillas // del sagrado Titicaca. // "Fui señor de veinte pueblos, // fui valido del Monarca: // soy ya juguete y escarnio // de implacable y fuerte raza. // Hijo, ;maldita la madre // que te dio su leche aciaga! // Y yo, jel padre sin ventura // que te dio existencia infausta! // Prole vil de viles senos, // ¿que te queda, qué te aguarda? // La servidumbre, el trabajo, // la mina oscura y helada..." // Se oye la queja de un niño, // un sordo choque en las aguas, // el rumor de lentos pasos, // y después, el eco, y nada. (GONZÁLEZ PRADA, 2004, p. 7374).
}

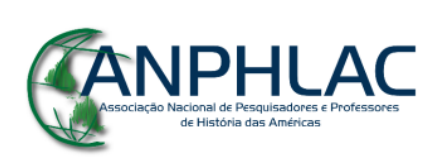

Revista Eletrônica da ANPHLAC, ISSN 1679-1061, №. 25, p. 161-182, Jul./Dez., 2018.

http://revista.anphlac.org.br 
Um aspecto interessante a ser observado é o de que, com exceção da balada Los tres - que representa personagens reais envolvidos com o território que veio a constituir o Estado peruano, como Manco Cápac, Francisco Pizarro e Simon Bolívar - nenhum outro protagonista envolvido nas tramas analisadas recebeu um nome próprio. Os sujeitos de suas poesias são sempre identificados de forma anônima, sendo chamados de "o índio"; "a índia"; "o branco" "o espanhol”, demarcando sempre a sua origem racial, cultural e social.

Observemos a balada La hija del curaca:

$$
\begin{gathered}
\text { Tardes e tarde pasea } \\
\text { el caballero español } \\
\text { por los floridos jardines } \\
\text { del Yacay encantador. } \\
\text { Escondida en su cabaña, } \\
\text { la virgen de sol, } \\
\text { tardes y tardes contempla } \\
\text { al gentil conquistador. } \\
\text { Tanto se vieron y vieron } \\
\text { virgen india y español, } \\
\text { que se abrazan en el fuego } \\
\text { de volcánica pasión. } \\
\text { “Hija infiel, exclama el padre, } \\
\text { al blanco tienes amor! } \\
\text { Ocultemos en los bosques } \\
\text { mi vergüenza y tu baldón.” } \\
\text { “Es el Yucay tan hermoso!” } \\
\text { ¡Es tan bello el español! } \\
\text { Quítame, oh padre, la vida, } \\
\text { mas no me quites de mi amor.” } \\
\text { La doncella marcha y marcha } \\
\text { de su padre anciano en pos, } \\
\text { y los tristes ojos vuelve } \\
\text { al Yucay encantador. } \\
\text { Por los bosques habitados } \\
\text { de la sierpe e el león, } \\
\text { in }
\end{gathered}
$$

\section{GANPHLAC}


andan y andan; mas un día

no caminan ya los dos.

Como se apaga una estrella,

como se agosta una flor,

muere la virgen indiana

al morir la luz del Sol.

Llenos los ojos de llanto,

llena el alma de dolor,

el curaca ante el cadáver

dice con risa feroz:

"Hallo en medio de mi pena

una gran consolación:

Se te fuiste y no eres mía,

no serás del español."

(GONZÁLEZ PRADA, 2004, p. 78-80).

$\mathrm{Na}$ balada acima, o amor entre o espanhol e a índia era verdadeiro. Simbolicamente, de tal paixão e desejo poderia surgir uma sociedade mestiça, em uma aliança harmônica entre as nobres indígenas e os soldados da Espanha, aparecendo a possibilidade de se construir uma sociedade coesa, com a legitimação dos frutos desta união. ${ }^{9}$ Contudo, o personagem do Curaca personificava todas as barreiras existentes na sociedade peruana entre a conciliação e harmonização dos índios com os espanhóis. Gonzalez Prada imaginou a existência de um pai que considerava uma desonra e uma traição para com seu próprio povo que a sua filha que se cassasse com um "conquistador".

Essa balada representa que o "mundo dos indígenas" e o "mundo dos ibéricos" estavam impossibilitados de se unirem de maneira legítima. O próprio título do poema "La hija del curaca", de antemão já demarca que a "virgen de sol" pertencia ao pai - o

\footnotetext{
${ }^{9}$ Portocarrero esclarece que durante o período colonial os "conquistadores" tiveram de abjurar as suas princesas indígenas para contrair matrimonio com as mulheres enviadas pela Coroa espanhola. Nessa conjuntura, os mestiços, filhos das índias com espanhóis, se converteram em bastardos, ilegítimos e repudiados (PORTOCARRERO, 2010. p. 222).
}

\section{GANPHLAC}

Revista Eletrônica da ANPHLAC, ISSN 1679-1061, №. 25, p. 161-182, Jul./Dez., 2018.

http://revista.anphlac.org.br 
curaca; um chefe político de uma comunidade indígena - e ao seu povo. As últimas estrofes dessa canção-história são: "se te fuiste y no eres mía, no seras del español", demonstrando que o personagem, o genitor da índia, preferia ver sua filha infeliz e morta a unida a um soldado inimigo e invasor. Ou seja, nessa história ficcional, independentemente da vontade da moça, ela pertencia ao pai e fazia parte do "mundo indígena" e, portanto, não se uniria de forma lícita com a linhagem e a "casta" dos espanhóis.

Passemos a refletir sobre a balada El chasqui:

Salta el Blanco de su lecho con la luz de nuevo día, y apercibe a la carrera su caballo de Castilla.

"Desiertos, montes y ríos de ti me apartan, Oh Elisa; más pisaré tu morada con la aurora vespertina.

Pronto, en marcha, imbécil indio, sé mi chasqui, sé mi guía: ve adelante a mi caballo; si cejas jay de tu vida!" “Piedad, piedad, Viracocha!” Clama el indio de rodillas; más el Blanco parte, vuela, y el sangriento azote vibra. El desierto se despliega como sábana infinita, con su Sol inexorable sus arenas agresivas. Ni una choza, ni una palma, ni una fuente, ni una brisa; que son llanuras de fuego los desiertos de las indias.

El animoso caballo doma sed, vence fatiga,

\section{GANPHLAC}


y con alas en el casco

El arenal desafía.

"!Piedad, piedad, Viracocha!"

clama el indio de rodillas;

más el blanco nada escucha

y el sangriento azote vibra. [...]

Mansa difunde la tarde

su roja luz mortecina,

y los muros de una estancia

entre flores se divisan.

El caballo arroja el viento

en relinchos de alegría,

$y$, al pie de férrea ventana,

la sudosa frente inclina.

En tierra salta el jinete

al indio arroja la brida,

un dulce nombre modula

y la bella estancia pisa.

En la sombra estalla un beso

y en campo un ay expira,

que delante del caballo

exhala el chasqui la vida.

(GONZÁLEZ PRADA, 2004, p. 75-78).

A mensagem da balada El chasqui foi a de que o branco era indiferente ao sofrimento do indígena. No caso desse poema, a frieza do espanhol ficou ainda mais ressaltada quando contrastada com o amor e a devoção que ele alimentava por uma jovem donzela. Nessa ficção criada por González Prada, o guia do ibérico deveria direcionar e acompanhar a corrida de um cavalo, enquanto era açoitado para manter o ritmo ao longo de um trajeto de mais de um dia de distância. Ao ver o índio implorar de joelhos por água e por um breve período de descanso, o branco se manteve insensível ao padecimento e ao penar do chasqui, em uma atitude verdadeiramente cruel.

Os versos de El chasqui expressaram a ideia de que o branco não via o indígena como um ser humano e um igual, mas como uma "coisa" que poderia ser tratada da

\section{GANPHLAC}


mesma maneira que um equino. Como não havia um reconhecimento da condição de humanidade do índio, inexistiam, consequentemente, sentimentos de piedade e de empatia para com o martírio de uma criatura "coisificada". Assim, com o personagem do indígena sendo destituído da sua humanidade aos "olhos" do protagonista espanhol, foi rebaixado ao "reino das bestas" até ter suas forças arrebatadas por completo, provocando a sua exaustão, inanição e morte.

Examinemos a balada El mitayo:

"Hijo, parto: la mañana reverbera en el volcán; dame el báculo de chonta, las sandalias de jaguar."

"Padre, tienes las sandalias, tienes el báculo ya; mas ¿por qué me ves y lloras? ¿A qué regiones te vas?"

"La injusta ley de los blancos me arrebata del hogar: voy al trabajo y al hambre, voy a la mina fatal." "Tú que partes hoy en día, dime, ¿Cuándo volverás?”

"Cuando el llama de las punas ame al desierto arenal."

“Cuándo el llama de las punas las arenas amará?"

"Cuando el tigre de los bosques beba en las aguas del mar." “¿Cuándo el tigre de los bosques en los mares beberá?"

"Cuando del huevo de un cóndor Nazca la sierpe moral." “¿Cuándo del huevo de un cóndor una sierpe nascerá?"

"Cuando el pecho de los blancos

\section{GANPHLAC}




\section{Se conmueva de piedad."}

“¿Cuándo el pecho de los blancos

piadoso y tierno será?"

"Hijo, el pecho de los Blancos

no se conmueve jamás."

(GONZÁLEZ PRADA, 2004, p. 80-81).

Em El mitayo, novamente González Prada construiu uma história na qual o branco não dava nenhum valor à vida do índio, uma vez que "o peito dos brancos não se comove jamais". Assim como na balada El chasqui, esses versos também transmitiram a ideia de que o indígena estava sendo obrigado a cumprir com uma tarefa que lhe custaria a vida, nesse caso, "ir ao trabalho e a fome"; "ir a mina fatal". Ainda podemos destacar que a inocência e a doçura das perguntas do filho, assim como a paciência, a ternura e a tristeza das respostas do pai, tinham a intencionalidade de induzir os leitores a se sensibilizarem com a situação de aguda exploração do trabalho do indígena.

A balada El mitayo é uma representação de um mundo em que o "complexo de inferioridade" já estava instalado no coração e na mente de parte dos indígenas. Nesse poema, vemos o índio entristecido indo contra a sua vontade trabalhar na "mina fatal", mas em momento algum dialoga com o rebento em tom de revolta, mas sim com resignação ante à injustiça. Sua passividade transmitiu ao seu menino a noção de que nada poderia ser feito para modificar aquela situação. O personagem do filho, por sua vez, simbolicamente representava as gerações futuras dos povos indígenas, que estavam sendo ensinadas, desde a mais tenra idade, a adotar uma postura de aceitação ante um sofrimento que era inevitável.

Passemos, por fim, à balada Los tres:

"En los Andes, grita Manco, del Oriente al occidente, sembraré grandeza y dicha con mi poder y mis leyes."

Y cruza llanos y sierras;

y, del Ocaso al Oriente, y, del Norte al Mediodía,

\section{GANPHLAC}

Revista Eletrônica da ANPHLAC, ISSN 1679-1061, №. 25, p. 161-182, Jul./Dez., 2018.

http://revista.anphlac.org.br 
reinan paz, ventura y bienes.

Exclama en Túmbez Pizarro:

"Es mi ley la ley del fuerte;

a mí la plata y el oro;

tiembla, oh Perú, y obedece."

$Y$ huella tierras del Inca,

y oro busca en su sed ardiente,

y, a su fierro paso, deja

el exterminio y la muerte.

En Roma, en el Capitolio,

Alza Bolivar la frente,

$y$ dice: "América, juro

tu libertad, o la muerte."

$Y$ vence mares y tierras,

y destroza densas huestes,

y da América redime

de españoles y de reyes

(GONZÁLEZ PRADA, 2004, p. 90-91).

Portocarrero afirma que Los tres é a balada que melhor expressa o intento de González Prada de construir uma "épica nacional" por ter recorrido a três figuras emblemáticas da história do Peru: Manco Cápac, Francisco Pizarro e Simon Bolívar: os três (re) fundadores da sociedade peruana.

Los tres encerrou o primeiro livro de Baladas. Na obra ficcional de González Prada, tais personagens históricos simbolizaram, cada um a sua maneira, um período da história do território peruano. O primeiro representava a idealização e a bemaventurança do Império dos Incas; o segundo personificava a ganância desmedida dos espanhóis ao longo do período colonial; o terceiro exprimia a exaltação da República e a promessa de que o Peru poderia se redimir e viver tempos melhores e mais justos.

Na balada Los tres, González Prada imaginou esses personagens históricos reproduzindo o gesto bíblico da Criação, pois com o poder do verbo, cada um deles transformou em realidade o seu desejo. O verbo criador de Manco Cápac é gritar, o de Pizarro é exclamar e o de Bolívar é dizer (PORTOCARRERO, 2010, p. 219). Na escrita

\section{GANPHLAC}


do intelectual, cada verbo proferido por esses avatares históricos anunciava uma realidade diferente para o território do Peru. O grito de Manco Cápac trouxe um mundo de paz, fartura, leis justas e ventura para todos. A exclamação de Pizarro, que representava os três séculos de período colonial, por outro lado, tinha uma intencionalidade oposta, gerando pânico, terror e submissão nos indivíduos que o escutavam. Por fim, González Prada deixou clara a sua admiração por Simon Bolívar, fantasiando o personagem proferindo palavras que anunciavam a libertação e a redenção de todo o sofrimento do povo peruano. Ao citar Bolívar, em seus últimos versos, demonstrou sonhar com um futuro melhor para a República, idealizando-a como uma força redentora que poderia transformar o status quo dos tempos coloniais.

Essas baladas observadas acima são fruto da imaginação de González Prada. Os personagens de suas tramas foram inventados. Mesmo aqueles que de fato existiram, como Manco, Pizarro e Bolívar, tiveram os seus comportamentos idealizados pelo imaginário do intelectual. Contudo, apesar da "épica nacional" criada por González Prada ser pura ficção, acreditamos que ela reflete a mentalidade e os valores da sociedade peruana do século XIX dos quais o escritor era parte e produto. Quando ele fantasiou histórias dos tempos coloniais, marcadas por um brutal conflito entre indígenas e espanhóis, estava levantando pertinentes questões que diziam respeito às problemáticas da sua própria época. Portanto, concebemos o primeiro livro de Baladas como sendo uma expressão de como o pensador interpretava os problemas sociais da sua contemporaneidade, quando os indígenas ainda permaneciam sendo explorados e inferiorizados, tal como no período colonial.

As baladas El chasqui e El mitayo transmitiram uma mensagem de condenação à estrutura social dos tempos coloniais, na qual o autor demarcou de forma maniqueísta a polarização entre os "brancos/dominadores/opressores" e os "índios/dominados/impotentes". Além disso, o "branco", nos versos do intelectual, deve ser pensado a partir uma perspectiva simbólica, representando o "conquistador", o dominador, o membro da elite opressora que impunha, por meio da força e da fraude, a sua hegemonia sobre todos os demais.

Como demonstramos na contextualização histórica de nosso artigo, González Prada estava inserido em um cenário no qual o novo Estado-nação foi incapaz de

\section{CANPHLAC}

Revista Eletrônica da ANPHLAC, ISSN 1679-1061, №. 25, p. 161-182, Jul./Dez., 2018.

http://revista.anphlac.org.br 
promover mudanças substanciais na estrutura social do Peru. As relações entre os membros da comunidade nacional continuaram sendo permeadas pelos costumes e hierarquias herdadas do período colonial. As elites dirigentes do Estado peruano, no contexto do século XIX, não foram capazes de forjar no imaginário coletivo sentimentos que irmanassem a todos os elementos participantes daquele território. As baladas expostas acima narram justamente histórias de um mundo marcado pela falta de identificação e empatia entre brancos e índios.

Para Portocarrero, a intencionalidade de González Prada ao elaborar as suas Baladas peruanas era construir uma épica nacional, buscando criar uma visão do conjunto da História do Peru. Entretanto, "el proyecto fracasa en la medida en que su propia realización pone en evidencia la falta de una 'substancia nacional' y, por tanto, la imposibilidad de imaginar, veraz e plausiblemente, una comunidad que integre a criollos e indígenas" (PORTOCARRERO, 2010, p. 218).

A partir da reflexão dos poemas acima, podemos concluir que a épica nacional construída em Baladas trouxe uma mensagem de que existiam dois mundos antagônicos, em conflito, e que não formavam uma comunidade harmônica no Peru: o "mundo dos índios" e o "mundo dos brancos". Ou seja, não existia a percepção de que os povos que habitavam o país formavam um "nós coletivo". Pelo contrário, os versos de González Prada ressaltaram o secular antagonismo, o ciclo de violência, a falta de união, de harmonia, de diálogo e de fraternidade entre os índios e os brancos.

Gostaríamos de frisar que o pensamento de González Prada foi sofrendo uma maturação ao longo dos anos. No primeiro livro de Baladas, composto entre 1871 a 1879, sua "épica nacional" trouxe uma mensagem de que o Peru ainda não formava uma nação, uma vez que historicamente o Estado abrigava dois mundos antagônicos e não integrados: o "mundo dos brancos" e o "mundo dos índios". Já em Discurso en el Politeama, de 1888, manifesto elaborado no cenário do Pós-guerra do Pacífico, seu posicionamento se modificou, pois assumiu um discurso ufanista, uma vez que convocou o povo peruano a amar a pátria e a sentir orgulho da sua própria gente e da sua terra natal. Dessa forma, o autor fez um chamado à aceitação, à união e à integração de todos os elementos que compunham aquela nação.

\section{GANPHLAC}


Em Discurso en el Politeama, ele promoveu uma ruptura com a tradição criolla e se afastou do legado etnocêntrico que sempre negou a existência do mundo indígena, consequentemente abrindo um novo horizonte para se imaginar o Peru (PORTOCARRERO, 2010, p. 215). Por sua vez, no escrito Nuestros indios, de 1904, González Prada foi uma das primeiras vozes na América Latina a contestar e fazer frente aos fundamentos do racismo científico e do darwinismo-social, rejeitando as ideias dominantes da sua contemporaneidade e apontando caminhos, mesmo que superficialmente, para transformar o status quo da vida dos índios e integrá-los à sociedade.

Não nos adentraremos em mais pormenores de Discurso en el Politeama e Nuestros indios, pois tais trabalhos são fontes documentais tão fecundas que exigem a elaboração de outros artigos a parte e o humilde propósito de nosso estudo é tão somente fazer uma reflexão de Baladas. Essa obra literária espelhou um "universo" socialmente estratificado, desunido e rígido, no qual o território peruano abrigava em seu seio "mundos" antagônicos e em conflito.

\section{Referências bibliográficas}

ANDERSON, Benedict. Comunidades imaginadas: Reflexiones sobre el origen y La difusión del nacionalismo. México, D.F: Fondo de Cultura Económica, 1993.

BALDÍN, César. Rastreando la participación indígena: pueblos de peruanos en la legislación electoral del siglo XIX. Elecciones, Lima, v. 8, n. 9, p. 61-86, 2009.

BECHELLI, Ricardo. A Guerra do Pacífico (1879-1883) e o pensamento antirracista de Manuel González Prada. Proj. História, São Paulo, n. 31, 2005. p. 362.

BONILLA, Heraclio; SPALDING, Karen. La Independencia en el Perú: las palabras y los hechos. In: BONILLA, Heraclio (org). La independencia en el Perú - Peru Problema. Lima: IEP, 1972, p. 15-64.

CANTANELI, Pedro. Manuel González Prada (1844-1918): História, debate e pensamento. Dissertação (Mestrado em História) - Universidade Estadual de Londrina, Londrina, p. 111. 2009.

\section{GANPHLAC}


CASTELLANOS, Isabelle. Prefacio. In: GONZÁLEZ PRADA, Manuel. Baladas. Lima: Editorial e Imprenta DESA S.A; Pontificia Universidad Católica del Perú, 2004, p. 7-16.

CHANG-RODRÍGUEZ, Eugenio. La influencia intelectual de Manuel González Prada. In: WARD, Thomas. El porvenir nos debe una victoria: La insólita modernidad de Manuel González Prada. Lima: Red para el Desarrollo de las Ciencias Sociales en el Perú, 2010, p. 67-79.

CONTRERAS, Carlos; CUETO, Marcos. Historia del Perú contemporáneo. Lima: IEP, 2007.

CONTRERAS, Carlos (org). Perú: crisis imperial e independencia. Tomo 1 - 18081830. Penguin Random House Grupo Editorial España, 2013. Disponível em: <https://books.google.com.pe/books?id=VYWjAAAAQBAJ\&pg=PT129\&lpg=PT129 $\& \mathrm{dq}=$ tributo+ind $\% \mathrm{C} 3 \%$ ADgena + Peru \&source $=$ bl\&ots $=\mathrm{C} 2 \mathrm{SAFisCWq} \& \operatorname{sig}=$ YohHa6n6 JNpeGUMp0Q4zyfcs72c\&hl=pt-

$\mathrm{BR} \& \mathrm{sa}=\mathrm{X} \& \mathrm{ved}=0 \mathrm{ahUKEwjerdq12NvUAhUDUZAKHQjzDec4FBDoAQhLMAc \# v=on}$ epage \&q=tributo\%20ind\%C3\%ADgena\%20Peru\&f=false $>$. Acesso em: jun. 2017, s/p.

GARAYAR, Carlos. Prólogo. In: PALMA Ricardo. Tradiciones peruanas. Lima: PEISA, 2001, p. 3-12.

GIL, Antonio Carlos. Projetos de Estado no alvorecer do Império. Vitória: Instituto Histórico e Geográfico do Espírito Santo, 2002.

GONZÁLEZ PRADA, Manuel. Baladas. Lima: Editorial e Imprenta DESA S.A Pontificia Universidad Católica del Perú, 2004.

GONZÁLEZ PRADA, Manuel. Discurso en el Politeama. In: GONZÁLEZ, PRADA, Manuel: Ensayos escogidos. Lima: Editorial Universo S.A, 1977, p. 21-27.

GONZÁLEZ PRADA, Manuel. Nuestros indios. In: GONZÁLEZ, PRADA, Manuel: Ensayos escogidos. Lima: Editorial Universo S.A, 1977, p.61-75.

GUERRA MARTINIÈRE, Margarita. Homenaje a José Antonio del Busto Duthurburu. Lima: Fondo editorial Pontificia Universidad Católica del Perú, 2012.

\section{GANPHLAC}


HOLGUÍN, Oswaldo. El largo camino de la nación peruana (siglo XIX). Revista Histórica, Lima, TOMO XLII, 2006.

JESUS, Graziela. “No soy um aculturado”: identidade nacional e indigenismo nas obras de Jose Maria Arguedas. Tese. (Doutorado em História) - Universidade Federal do Espírito Santo. Vitória, p. 214. 2015.

MARIÁTEGUI, José Carlos. 7 ensayos de interpretación de la realidad peruana. Lima: Impresiones Comerciales de Empresa Editorial El Comercio S.A, 2005

MASSAUD, Moisés. Dicionário de termos literários. São Paulo: Cultrix, 2004.

PORTOCARRERO, Gonzalo. El indio como prójimo: González Prada y el nacimiento de la tradición democrática en el Perú. In: WARD, Thomas. El porvenir nos debe una victoria: La insólita modernidad de Manuel González Prada. Lima: Red para el Desarrollo de las Ciencias Sociales en el Perú, 2010, p. 215-228.

SCHWARCZ, Lilia. Imaginar é difícil (porém necessário). In: ANDERSON, Benedict. Comunidades imaginadas: reflexões sobre a origem e a difusão do nacionalismo. São Paulo: Companhia das letras, 2008, p. 10-16.

SILVA, Tomaz Tadeu. A produção social da identidade e da diferença. In: SILVA, Tomaz Tadeu. Identidade e diferença: a perspectiva dos estudos culturais. Petrópolis: Editora Vozes, 2012.

SOUZA, Tito Eugênio. Manuel González Prada e o surgimento de uma "nova consciência" do Peru. Caderno de Letras, Pelotas, n. 25, jul-dez, p. 125-140, 2015.

TORD, Luis Enrique. El indio en los ensayistas peruanos (1848-1948). Lima: Editoriales Unidas S.A, 1978.

\section{GANPHLAC}

Revista Eletrônica da ANPHLAC, ISSN 1679-1061, №. 25, p. 161-182, Jul./Dez., 2018.

http://revista.anphlac.org.br 